\section{Finding clues in cities: nest site selection by house sparrows across a varied habitat matrix in Delhi, India}

\author{
Shikha Choudhary ${ }^{1} *$, N. P. S. Chauhan ${ }^{1}$ and \\ Rajiv Kalsi ${ }^{2}$ \\ ${ }^{1}$ Amity Institute of Forestry and Wildlife, Amity University, \\ Sector-125, Noida 201 301, India \\ ${ }^{2}$ Department of Zoology, Mukand Lal National College, \\ Yamuna Nagar, Haryana 135 001, India
}

With changing urbanization pattern and architectural style, the house sparrow is rapidly losing its nesting ground leading to a drastic decline in its population. We studied the sparrow nest site selection to make recommendations to the Forest Department and NGOs in the conservation of sparrows in Delhi, India. Active nests were located across the habitat matrix in East Delhi. The maximum number of nests was found in suburban and high-density urban areas. The most preferred place for nesting was rolling shutters and wall crevices. The presence of old buildings, vegetation patch, water source, grocery shops, food provisioning, open drains and open dumps influence the sparrow nest selection site. By conserving natural habitat and installing nest boxes at suitable places, the sparrows can be conserved.

Keywords: Habitat matrix, house sparrow, nest site selection, urban birds.

NEST site selection is an important decision in the life of birds. The nest site and nest patch are the two main spatial scales on which this decision is based ${ }^{1}$, which includes social and physiognomic features of the surroundings ${ }^{2}$ influenced by the availability of food and water, predation, competition and nest ectoparasites ${ }^{3}$. A well-chosen nest site not only determines successful rearing of the clutch ${ }^{4}$, but also has an impact on the health of the parents and nestlings ${ }^{1,5}$.

Disturbances caused by man-made structures can have an effect on nest site selection, while the ability of different birds to adjust to such disturbances leads to the nest distribution of a bird's community, and this might favour human-associated bird species ${ }^{6}$. Urbanization along with climate change is considered as a major threat to the persistence of many birds ${ }^{7}$. Habitat loss and fragmentation are the foremost threats due to urbanization, which either leads to migration of birds to more suitable habitats or adaptation to new conditions ${ }^{8,9}$. Passerines generally show a high degree of evolutionary conservatism in their nesting behaviour ${ }^{10}$; the house sparrow is known to adapt and exploit urban resources well ${ }^{11,12}$. According to some researchers, the sparrow is a symbiotic species with

*For correspondence. (e-mail: shikhachoudhary03@gmail.com) humans. It is closely associated with humans and depends on them for food and shelter and in turn, it has educational, recreational, economic and aesthetic values ${ }^{13}$.

Although in the 'least concern' category on the IUCN Red List ${ }^{14}$, the sparrow has shown a drastic decline in population in urban centres all over the world in recent decades ${ }^{15,16}$. The primary cause of this decline has not been ascertained, but a number of hypotheses have been put forth, including a reduction in nest site availability ${ }^{17}$. Studies suggest that this decline might be due to smallscale habitat changes which in turn might lead to a reduction in the availability of suitable foraging and nesting habitat $^{18}$. A successful conservation strategy largely depends on acquiring an accurate understanding of the habitat requirements of the species. Studies have reported differential nest site selection among house sparrows which leads to subsequent differences in productivity among sites ${ }^{19,20}$. In this context, the present study was undertaken to identify the habitat variables influencing the selection of nest sites, so that artificial nest boxes can be installed in selected sites to ensure full utilization of resources. By conserving preferred natural sites, we can conserve and help re-establish the house sparrow population.

East Delhi $\left(28^{\circ} 38^{\prime} 24^{\prime \prime} \mathrm{N}, 77^{\circ} 17^{\prime} 24^{\prime \prime} \mathrm{E}\right)$ is one of the most populated $(26,179$ persons per sq. $\mathrm{km})$ and congested zones of Delhi, India. It has a total area of $64 \mathrm{sq}$. km with a mosaic of urban, suburban and agricultural areas (Figure 1). The human population according to the 2011 census is 16,753,235 (ref. 21). East Delhi was selected as the study area because it is small and has varied habitat types. The small study area enabled us to make frequent field surveys, thus increasing the probability of nest detection. There was also a population of house sparrows resident in East Delhi (from personal observations and discussions with birders in Delhi), which helped generate data for subsequent analyses.

The study area was divided into $1 \mathrm{~km} \times 1 \mathrm{~km}$ grids as the sparrows do not disperse more than $200-600 \mathrm{~m}$ once their eggs are laid ${ }^{22}$. A total of 58 transects $(500 \mathrm{~m}$ long and $10 \mathrm{~m}$ wide) were laid, one transect in each grid, taking utmost care to maintain homogeneity of habitat type (Figure 2). The number of transects was proportional to the area occupied by each habitat type: agriculture area $(\mathrm{AR})=12$ transects; low-density urban area $($ LDUA $)=7$, medium-density urban area $($ MDUA $)=11$, high-density urban area $($ HDUA $)=18$ and suburban area $($ SUA $)=10$. High, medium and low-density urban areas were differentiated based on the density of houses or buildings present in them ${ }^{22}$.

The repeated monthly surveys (total time devoted = $810 \mathrm{~h}$ ) were conducted in the morning from 0600 to $0900 \mathrm{~h}$ to locate active sparrow nests (parents carrying food for the nestlings or nestlings making a call) during the breeding period (September-October 2017 and February-August 2018). For every active nest, the 


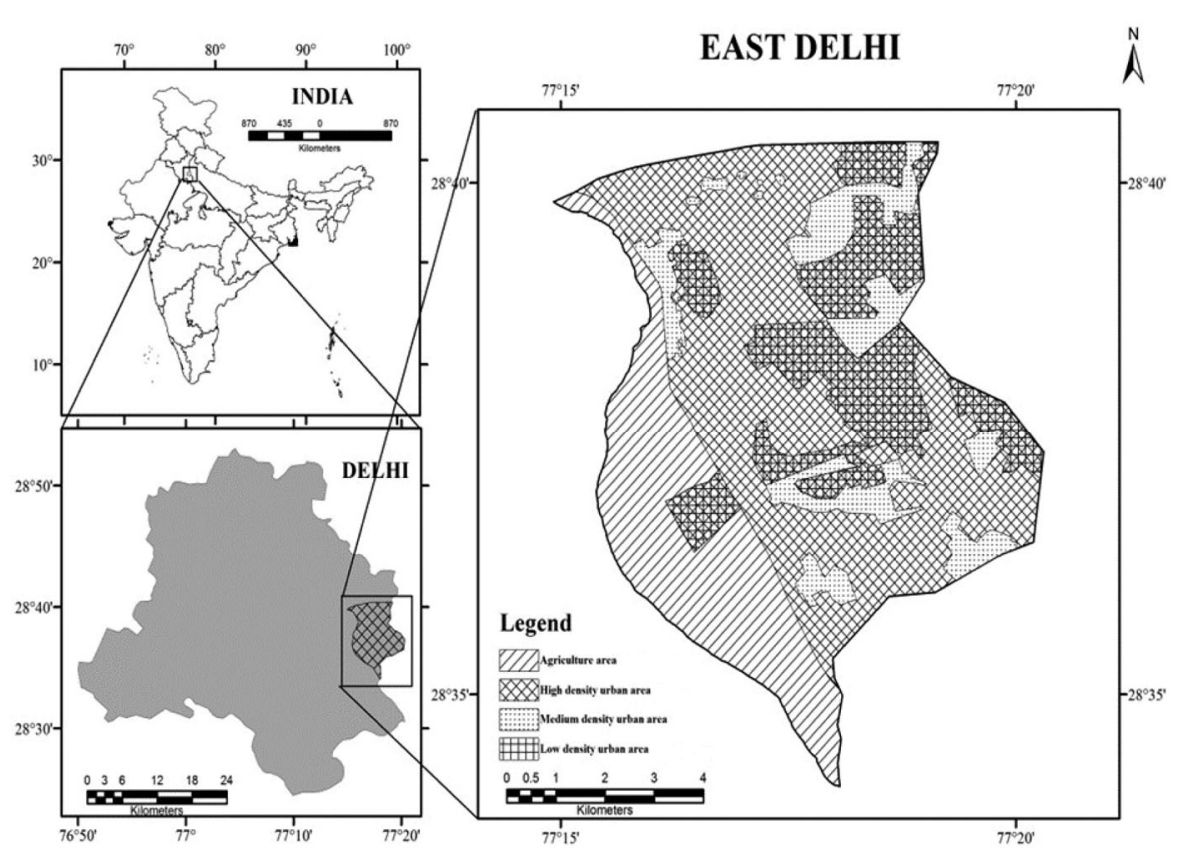

Figure 1. Location map of the study area and broad classification of varied habitat types of East Delhi, India.

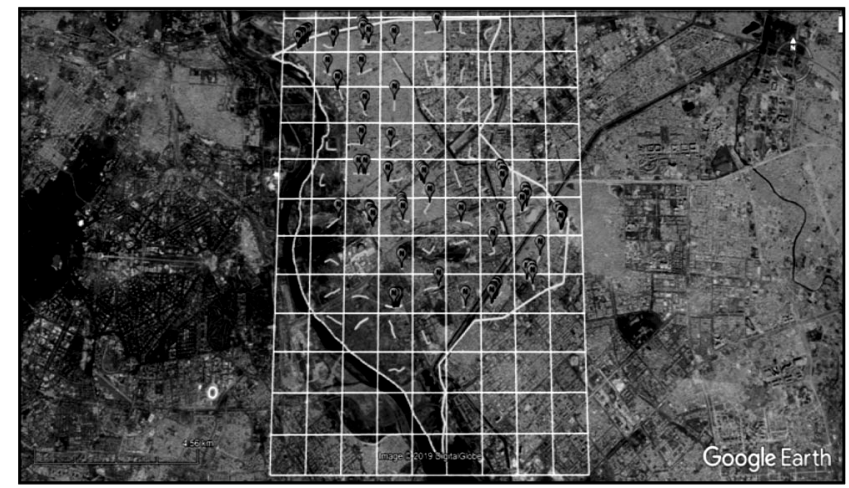

Figure 2. Google Maps image showing grid system, 58 transects and locations of house sparrow nests in the study area during 2017-18.

following habitat variables were recorded: habitat type (AR/HDUA/MDUA/LDUA/SUA), macro site (residential area/shops/school/park/open area/agricultural area/plant nursery/vegetable market/offices), type of buildings, distance to the nearest vegetation patch (ranging from a single tree/shrub/creeper/herb to cluster of trees/shrubs/ creepers/herbs), vegetation type, distance to a water source (presence of leaking taps, hand pump, bird water pots), grocery shops, small eateries and food provisioning (grains kept by people for birds in general), presence of other bird species (sighted near house sparrow nests while walking the transect), nest placement (house/shop/ office/metro station/bridge, etc.), substrate used (rolling shop shutter/wall crevices/air-conditioner/artificial nest box/iron rod/electric metre box), height from the ground, type of drainage system (open/closed), and type of household waste disposal system (open dump/no dump) within a radius of $50 \mathrm{~m}$ from the sparrow nest. To check the nest-site availability, the above-mentioned habitat variables were recorded within $50 \mathrm{~m}$ radius at every $100 \mathrm{~m}$ on 58 transects (total points $=348$ ). GPS locations of all the active nests were recorded (Figure 2) using a handheld Global Positioning Unit (Garmin Etrex20X).

Data were analysed using SPSS v. 25 and graphs were plotted using Microsoft Excel. As data were not normally distributed, non-parametric Kruskal Wallis $H$ test was used to check for any similarities or dissimilarities in the distances of available habitat variables (distance to vegetation patch, water source, grocery shops, small eateries, food provisioning, and height of the nest from the ground) from the nests across the habitat matrix.

Nest habitat data for available and used sites were arranged according to different habitat types. The Pearson correlation matrix was computed to check for multicollinearity among different habitat variables (habitat types, types of buildings, presence of vegetation, water, grocery shops, small eateries, food provisioning, type of drainage system and type of household waste disposal system). Multinomial logistic regression was used to quantify how the habitat variables influenced the selection of nesting sites by the sparrows.

The phi coefficient matrix (dichotomous data) was computed to check the degree of association between different habitat variables (macro site, vegetation type and other bird species) and nest presence.

A total of 122 nests were recorded, with maximum nests in suburban areas $(53.46 \%)$ followed by highdensity urban areas (Figure $3 a$ ). There was significant 

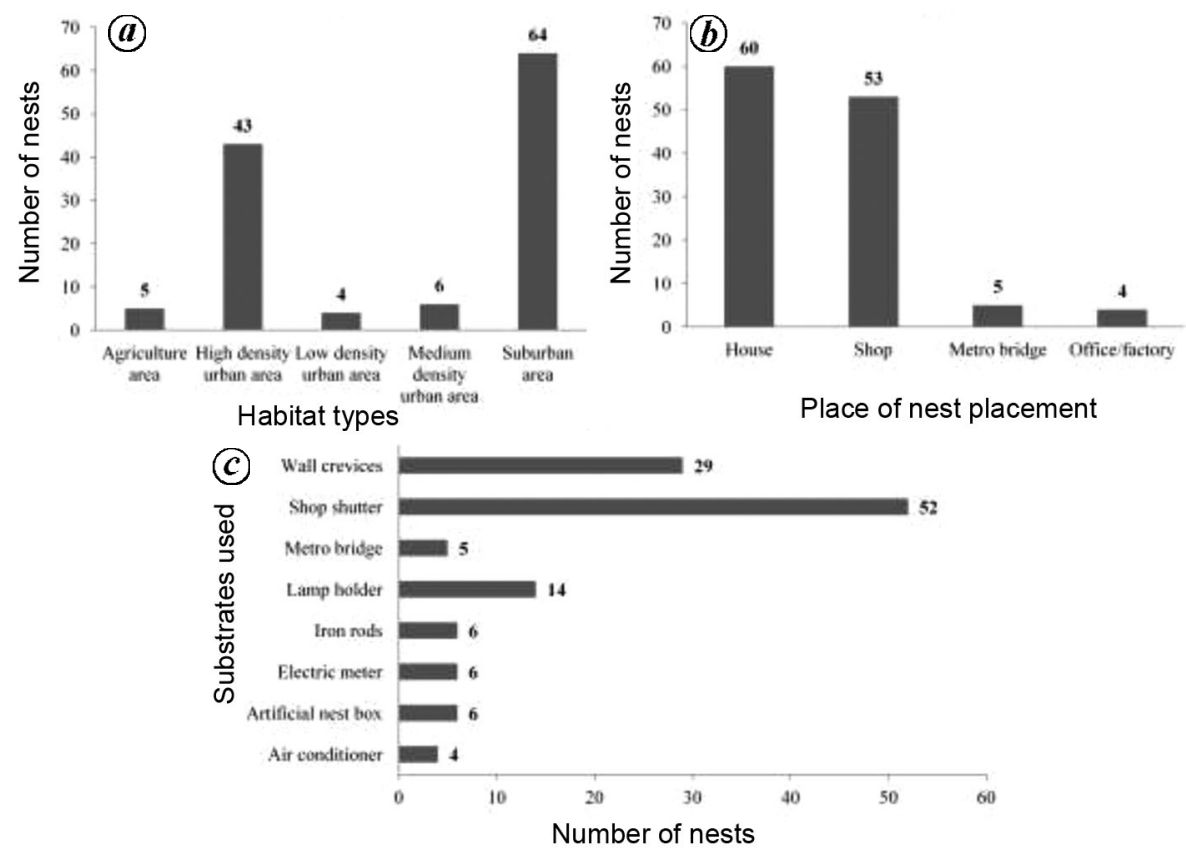

Figure 3. Bar diagram showing the number of house sparrow nests across different (a) habitat types, (b) different nest placement sites and (c) substrates used for nest-making in East Delhi (2017-18).
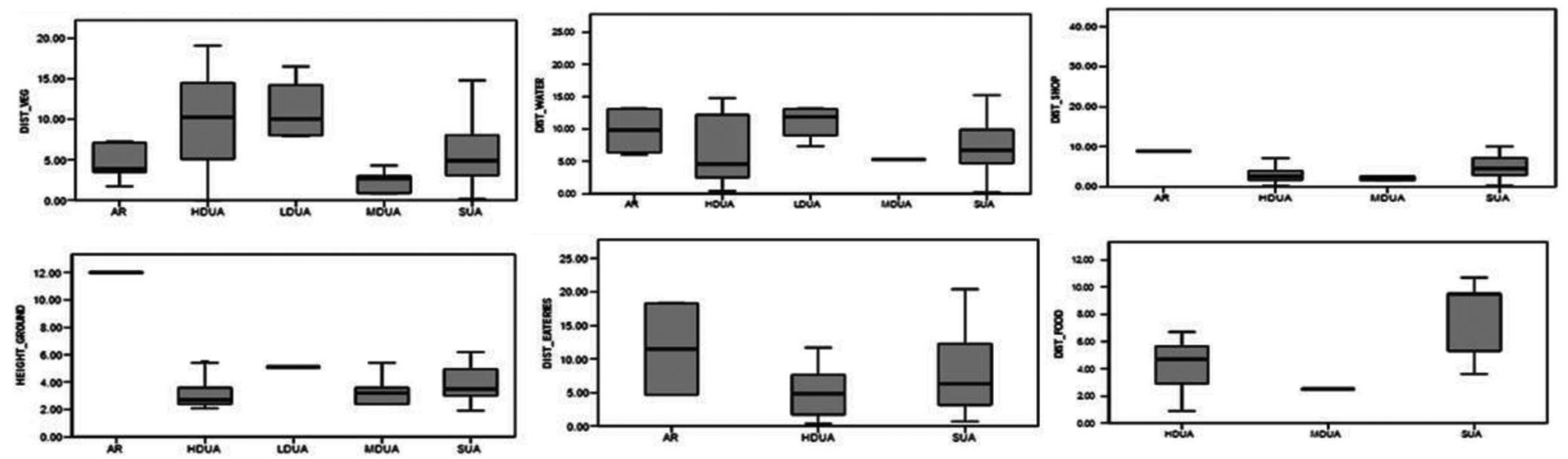

Figure 4. Distance $(\mathrm{m})$ of different habitat variables from house sparrow nests across the habitat matrix. DIST_VEG, Distance to vegetation; DIST_WATER, Distance to water source; DIST_SHOP, Distance to grosery shop; DIST_GROUND, Height of nest from ground; DIST_EATERIES, Distance to small eateries and DIST_FOOD, Distance to food provisioning.

difference in the number of nests present in different habitat types $\left(\chi^{2}=147.669, \mathrm{~d} f=4, P \leq 0.0001\right)$.

The site of nest placement $\left(\chi^{2}=89.437, \mathrm{~d} f=3\right.$, $P \leq 0.0001)$ and preference of substrate $\left(\chi^{2}=133.077\right.$, $\mathrm{d} f=7, P \leq 0.0001)$ varied significantly across habitats. Of the total 122 nests, $49.18 \%$ were built in houses while $43.44 \%$ nests were built in shops (Figure $3 b$ ).

The most preferred substrate was rolling shop shutters (42.62\%), followed by wall cavities (Figure $3 c$ ).

The distance to vegetation $\left(\chi^{2}=17.129, \mathrm{~d} f=4\right.$, $P=0.002, N=97)$, grocery shops $\left(\chi^{2}=12.465, \mathrm{~d} f=4\right.$, $P=0.006, \quad N=73)$ and height from the ground $\left(\chi^{2}=24.946, \mathrm{~d} f=4, P=0.000, N=108\right)$ varied significantly for sparrow nests in different habitats (Figure 4).
Table 1 shows the mean distance between the nests and various habitat variables. The majority of sparrow nests were within $<10 \mathrm{~m}$ from the nearest vegetation patch $(73.19 \%)$, water source $(68.57 \%)$ or grocery shop $\left(95.94 \% ; \chi^{2}=18.58559, \mathrm{~d} f=2, P \leq 0.0001\right)$. Most nests $(70.37 \%)$ were within $<5 \mathrm{~m}$ height from the ground $\left(\chi^{2}=\right.$ 97.8074, $\mathrm{d} f=1, P \leq 0.0001)$.

According to the minimum adequacy model $(\triangle \mathrm{AIC}=$ $\left.193.288, \chi^{2}=238.500, \mathrm{~d} f=14, P<0.001\right)$ at $95 \%$ confidence interval, nest site selection by sparrows is a function of the habitat type (HDUA, MDUA and SUA), presence of old buildings, vegetation patch, water source, grocery shops, food provisioning, open drainage systems and open waste dumps (Table 2). 


\section{RESEARCH COMMUNICATIONS}

Based on the phi coefficient matrix the presence of sparrow nests was positively correlated with residential area $(r=0.483, P=0.000)$, grocery shops $(r=0.397$, $P=0.000)$, shrubs and creepers $(r=0.417, P=0.000)$, whereas a negative influence was observed from agricultural areas, presence of myna and parks (Table 3). Lawsonia inermis (mehendi), Ziziphus mauritiana (ber), Combretum indicum (rangoon creepers) and Bougainvillea glabra (bougainvillea) were the most preferred vegetation type (on 73 out of 111 occasions, sparrow nests were found near one of these plant species).

House sparrows have shown significant differences in the selection of habitat type for nest-making ${ }^{23}$. In this study, house sparrows showed a strong preference for suburban and high-density urban areas to construct nests. Heij ${ }^{19}$ reported a positive correlation between house sparrow density and human population across an urban-rural gradient. Weqgrzynowicz ${ }^{24}$ reported that the number of sparrow pairs correlated to the area covered by buildings; with larger areas under buildings increasing the availability

Table 1. Mean distance of house sparrow nest to different habitat variables in East Delhi, India during 2017-18

\begin{tabular}{lcc}
\hline Habitat variable & Mean \pm SEM $(\mathrm{m})$ & Range $(\mathrm{m})$ \\
\hline Vegetation & $7.26 \pm 0.50$ & $0-19.1$ \\
Water source & $7.44 \pm 0.57$ & $0.2-21.1$ \\
Grocery shop & $4.50 \pm 0.32$ & $0.2-12.3$ \\
Small eateries & $6.98 \pm 0.55$ & $0.4-20.4$ \\
Food provision & $5.42 \pm 0.48$ & $0-11$ \\
Ground & $4.05 \pm 0.20$ & $2.4-12$ \\
\hline
\end{tabular}

Table 2. Results of multinomial logistic regression showing the influence of different habitat variables on sparrow nest site selection

\begin{tabular}{lccc}
\hline Habitat variable & $B$ & SE & $P$ \\
\hline Intercept & -17.26 & 0.698 & 0.000 \\
Habitat type & & & \\
$\quad$ HDUA & -2.88 & 0.830 & 0.001 \\
$\quad$ MDUA & -2.32 & 0.970 & 0.017 \\
LDUA & -2.30 & 1.38 & 0.096 \\
SUA & -2.32 & 0.871 & 0.008 \\
AR & $0^{\mathrm{b}}$ & - & - \\
Type of building & & & \\
$\quad$ Old & 1.129 & 0.410 & 0.006 \\
$\quad$ New & -16.04 & 1107.54 & 0.988 \\
$\quad$ Mud houses & $0^{\mathrm{b}}$ & - & - \\
Vegetation & & & \\
$\quad$ Present & 15.755 & 0.471 & 0.000 \\
$\quad$ Absent & 14.18 & 0.000 & - \\
Water (present) & 1.272 & 0.369 & 0.001 \\
Grocery shop (present) & 1.844 & 0.478 & 0.000 \\
Small eateries (present) & -0.486 & 0.376 & 0.197 \\
Food provision (present) & 1.93 & 0.769 & 0.012 \\
Drainage system (open) & -1.031 & 0.535 & 0.054 \\
Household waste (open dump) & 3.432 & 0.574 & 0.000 \\
\hline
\end{tabular}

$B$, Coefficient for the constant; SE, Standard error; $0^{\mathrm{b}}$, Redundant variables. of nest sites in the form of holes and crevices. Bengtson et $a l{ }^{25}$ reported a highly significant positive correlation between the number of houses and abundance of house sparrows. Old buildings ${ }^{26}$, conventional grocery shops ${ }^{27}$, open drainage systems ${ }^{28}$, and open household waste dumps ${ }^{16}$ were shown to be perfect sites for sparrows.

Sparrow nestlings are generally fed with aphids, weevils, caterpillars and grasshoppers ${ }^{16}$, which are easily available in open dumps and drainage systems. Anandan et $a l .{ }^{29}$ and Nath et al. ${ }^{28}$ have reported that mosquito larvae were picked by sparrows from stagnant water available near houses (mostly drainages). Low-density areas were avoided for nesting as they had new constructions ${ }^{30}$, well-managed waste disposal systems, closed drainage systems and no grocery shops. Other reasons might be the small population size, stochastic events, predation and Allee effects ${ }^{25}$. Modern buildings fully covered with glass or fibre did not provide any nesting space ${ }^{1,16,17}$, which might lead to their migration to other areas ${ }^{31}$ or their local extinction. Shaw ${ }^{18}$ reported that in urban areas, the distribution of house sparrows was often patchy and dependent on the socio-economic status of the local human population. Agricultural areas were also not preferred due to lack of nesting sites. Though there were mud houses, they were all covered with thick tarps, leaving no space for sparrows to make nests. Also, the height of houses was not more than $5.5 \mathrm{ft}$ (around $1.7 \mathrm{~m}$ ), making them prone to predation and other disturbances.

Sparrows prefer small and confined places to construct nests $^{28}$. The majority of nests are found in man-made structures like rolling shop shutters ${ }^{27}$ and wall crevices ${ }^{24}$, as they are not exposed to the vagaries of nature, competitors and predators. With increased urbanization, sparrows have started to explore new substrates like AC

Table 3. Result of phi coefficient showing correlation of different macro sites, type of vegetation and other bird species on the presence of sparrow nests in East Delhi

\begin{tabular}{lrl}
\hline & $r$ & Sigma \\
\hline Macro sites & & \\
Residential area & 0.483 & 0.000 \\
Shops & 0.397 & 0.000 \\
School & 0.022 & 0.794 \\
Park & -0.240 & 0.004 \\
Vegetable market & 0.076 & 0.366 \\
Open area & 0.033 & 0.696 \\
Agricultural area & -0.419 & 0.000 \\
Plant nursery & -0.135 & 0.108 \\
Offices & -0.195 & 0.019 \\
Vegetation types & & \\
Trees & -0.210 & 0.000 \\
Shrubs and creepers & 0.417 & 0.000 \\
Herbs and grasses & 0.144 & 0.004 \\
Other bird species & & \\
Pigeon & -0.003 & 0.975 \\
Crow & -0.260 & 0.002 \\
Myna & -0.434 & 0.000 \\
\hline
\end{tabular}


exhausts, hanging lamp holders, installed artificial nest boxes $^{27}$, metro stations and bridges under construction. House sparrows may have adapted to some extent to the changing architectural style ${ }^{27,28}$.

Nests in proximity of resources were probably built to maximize efforts rather than wasting energy in foraging distant grounds and leaving nests unattended for longer periods. The majority of nests were within $10 \mathrm{~m}$ from a vegetation patch, water source or grocery shop. Since most of the nests were within $5 \mathrm{~m}$ from the ground, it might be inferred that the sparrows prepared intermediate height for nest-making. Nath et $a l^{28}$ reported similar height preference for nest-making by sparrows in Assam. It might be noted that at this height, nests are outside the reach of predators and other destructive agents, and also not so high to hinder sparrows in maximizing their efforts. McGillivray ${ }^{5}$ has reported a negative correlation between the weight of house sparrow fledglings and nestlings, and nest height. Distance to vegetation or grocery shops varied significantly for different habitat types. Distance to the nearest vegetation patch was lower in agricultural areas, medium-density urban areas and suburban areas in comparison to high-density and low-density urban areas. This was probably due to the unavailability of green cover in these areas. Proximity to grocery shops was lower in high- and medium-density urban areas compared to suburban and agricultural areas. The reason might be the availability of grocery shops, as majority of the buildings in high-density urban areas have grocery shops on the ground floor and residences on the first and second floors, whereas a limited number of shops is found in agricultural areas. Distance to water and food provisioning did not vary across the habitat matrix, as majority of houses kept water and grains for birds in general. High-density urban areas have several small eateries to cater to a large population; so the distance to small eateries was less in these areas compared to others.

Among macro sites, residential area ${ }^{24,32}$, grocery shops ${ }^{27}$, school, open areas and vegetable market showed a positive correlation with the presence of sparrow nests, as they provided adequate food and nesting sites. The presence of parks, agricultural areas (mostly olericulture, i.e. vegetable farming) and plant nurseries had a slightly negative influence on the presence of house sparrow nests. The reason might be the unavailability of foraging sites ${ }^{32}$, suitable nesting sites, the presence of predators (cats and snakes) or competitors (myna and jungle babblers), use of pesticides and the homogenous nature of parks. Many studies have shown the importance of home gardens, which provide food for house sparrow nestlings ${ }^{18,32}$. In the present study, the role of home gardens (mostly absent in the study area) in the provisioning of food was fulfilled by open drainages, open waste dumps and vegetation patches. Public parks, though present, were not preferred as they were homogenous and intensively managed. Shaw ${ }^{18}$ reported that small green patches between high-rise buildings were of less value to the sparrows than home gardens. However, we observed that small patches of vegetation in high-density urban areas were useful for both adult sparrows and nestlings. Medium-sized shrubby vegetation provided cover during foraging and roosting, and safety from predators to fledglings while learning to hop and $\mathrm{fly}^{33}$.

Presence of the common myna had a negative impact on the presence of sparrow nests. Myna being a cavitynester competes with house sparrows for nest $\operatorname{sites}^{34}$ and food sources ${ }^{35}$. It is aggressive and larger in size, and thus out-competes the sparrow. Hence, majority of sparrow nests had a few mynas in their proximity. Khera et $a l .{ }^{22}$ observed similar results of the negative impact of mynas on house sparrows. Crows had a slight negative impact as predators of eggs or nestlings, though it was difficult for them to reach the nests as they were made in confined places with low visibility from the outside ${ }^{22}$. Hence the presence of crows near their nests may be tolerated to some extent by the sparrows. Pigeons showed no impact on sparrow nests, as the nest site requirements for both the species are different.

In this study, we observed a clear pattern in nest site selection by house sparrows across a varied habitat matrix in East Delhi. High rates of sparrow nests were reported from suburban and high-density urban areas owing to factors like availability of food and nesting grounds. Old buildings provided suitable nesting sites, while the presence of conventional grocery shops, small eateries, food provisioning, open drainages and open household dumps provided food for both adult sparrows and nestlings. Medium-sized shrubby vegetation along with providing insect diet to the nestlings, also provided escape cover and roosting place for the sparrows. By installing artificial nest boxes at suitable places and by food provisioning the house sparrows can be conserved. Further studies on nest monitoring are required to determine how site selection influences nesting-success.

1. Singha, H., Deb, P., Chakdar, B., Roy, J. K. and Choudhury, M. R., Nest site selection by passerines with special reference to house sparrow (Passer domesticus) and spotted munia (Lonchura punctulata) in a newly developed semi-urban hamlet in south Assam. Assam Univ. J. Sci. Technol.: Boil. Environ. Sci., 2011, 8(1), 74-83.

2. Burger, J., Habitat selection in temperate marsh-nesting birds. In Habitat Selection in Birds (ed. Cody, M. L.), Academic Press, San Diego, 1985, pp. 253-281.

3. Sohi, G. K. and Kler, T. K., Adaptations in avian nesting behaviour in relation to indigenous trees and housing structures in Punjab. J. Entomol. Zool. Stud., 2017, 5(5), 1045-1051.

4. Clark, R. G. and Shutler, D., Avian habitat selection: pattern from the process in nest site use by ducks? Ecology, 1999, 80, 272-287.

5. McGillivray, W. B., Climatic influences on productivity in the house sparrow. Wilson Bull., 1981, 93(2), 196-206.

6. Remacha, C. and Delgado, J. A., Spatial nest-box selection of cavity-nesting bird species in response to proximity to recreational infrastructures. Landsc. Urban Plann., 2009, 93, 46-53. 


\section{RESEARCH COMMUNICATIONS}

7. Isaksson, C., Impact of urbanization on birds. In Birds Species. Fascinating Life Science (ed. Tietze, D.), Springer, Cham, Switzerland, 2018, pp. 235-257.

8. Marzluff, J. M. and Ewing, K., Restoration of fragmented landscape for the conservation of birds: a general framework and specific recommendation for urbanizing landscapes. Restor. Ecol., 2001, 9, 280-292.

9. McKenney, M. L., Urbanization, biodiversity and conservation. Bioscience, 2002, 52, 883-890.

10. Price, J. J. and Griffith, S. C., Open cup nests evolved from roofed nests in the early passerines. Proc. R. Soc. London, Ser. B, 2017, 284(1848), 20162708.

11. Sheldon, E. L. and Griffith, S. C., A high incidence of non-cavity nesting in an introduced population of house sparrows suggests that the species should not constrained by cavity nest site availability. Avian Res., 2017, 8, 29.

12. Anderson, T. R., Biology of the Ubiquitous House Sparrow: From Genes to Populations, Oxford University Press, Oxford, UK, 2006.

13. Ghosh, S., Ki, H. K. and Bhattacharya, R., A survey on house sparrow population decline at Bandel, West Bengal, India J. Korean Earth Sci. Soc., 2010, 31(5), 448-453.

14. BirdLife International, Passer domesticus (amended version of 2017 assessment). The IUCN Red List of Threatened Species, 2018, e.T103818789A129643357.

15. Balmori, A. and Hallberg, O., The urban decline of the House Sparrow (Passer domesticus): a possible link with electromagnetic radiation. Electromagn. Biol. Med., 2007, 26(2), 141-151.

16. Crick, H. Q. P., Robinson, R. A., Appleton, G. F., Clark, N. A. and Rickard, A. D., The investigation into the causes of the decline of starlings and house sparrows in Great Britain. BTO Research Report 290, Defra, London, 2002.

17. Summers-Smith, J. D., The decline of the house sparrow: a review. Br. Birds, 2003, 96, 439-446.

18. Shaw, L. M., Investigating the role of socioeconomic status in determining urban habitat quality for the house sparrow (Passer domesticus), Ph D thesis, The University of Exeter, UK, 2009.

19. Heij, C. J., Comparative ecology of the house sparrow (Passer domesticus) in rural, suburban and urban situations. $\mathrm{Ph} \mathrm{D}$ thesis, University of Amsterdam, The Netherlands, 1985.

20. Seress, G., Bókony, V., Pipoly, I., Szép, T., Nagy, K. and Liker, A., Urbanization, nestling growth and reproductive success in a moderately declining house sparrow population. J. Avian Biol. 2012, 43, 403-414.

21. https://www.census2011.co.in/census/city/49-delhi.html

22. Khera, N., Das, A., Srivastav, N. and Jain, S., Habitat wise distribution of house sparrow, Passer domesticus in Delhi, India. Urban Ecosyst., 2010, 13(1), 147-154.

23. Chaudhari, H. J., Nest site selection by house sparrow Passer domesticus (Linnaeus, 1758). Master's thesis, Anand Agricultural University, Gujarat, 2016.

24. Węgrzynowicz, A., Importance of nest sites availability for abundance and changes in the number of houses and tree sparrow in Warsaw. Int. Study Sparrows, 2012, 36, 56-65.
25. Allee, W. C., The Social Life of Animals. W. W. Norton, New York, 1938.

26. Balaji, S., Baskaran, S., Rajan, M. K. and Pavaraj, M., Investigating the causes for the decline and strategies to conserve house sparrow. Passer domesticus in Sivakasitaluk, Virudhunagar district, Tamil Nadu, India. World J. Zool., 2013, 8(3), 278-284.

27. Balakrishnan, P., Jijeesh, N., Kurikkal, M. S., Maya, T., Lijitha, M. P., Bhaskar, R. R. and Vipeesh, N., Distribution, abundance and nest site characteristics of the house sparrow (Passer domesticus) in Manjeri municipality, Kerala. Technical Report, Wildlife Research and Conservation Trust, NSS College, Manjeri, Kerala, 2011.

28. Nath, A., Singha, H., Deb, P., Das, A. K. and Lahkar, B. P., Nesting in a crowd: the response of house sparrow towards proximity to spatial cues in commercial zones of Guwahati city. Proc. Zool. Soc., 2015, 69, 249-254.

29. Anandan, G. et al., The house sparrow is homeless: a small attempt to conservation. J. Biodivers. Endanger. Species, 2014, 2, 124.

30. Shaw, L. M., Chamberlain, D. and Evans, M., The house sparrow Passer domesticus in urban areas: reviewing a possible link between post-decline distribution and human socioeconomic status. J. Ornithol., 2008, 149, 293-299.

31. Menon, M., Devi, P. and Mohanraj, R., Habitat variability and spatial assemblages of house sparrow Passer domesticus along a gradient of urbanization. J. Environ. Sci., Toxicol. Food Technol., 2013, 4(4), 1-11.

32. Kanaujia, A., Kumar, A., Kushwaha, S. and Kumar, A., Spatial distribution and habitat preference of the house sparrow, Passer domesticus in the urban, semi-urban and rural landscape of Lucknow and its neighbouring areas, Uttar Pradesh, India. Biodivers. Environ., 2015, 57(2), 182-188.

33. Dhanya, R. and Azeez, P. A., The house sparrow (Passer domesticus) population of Arakku township, Andhra Pradesh, India. Indian Birds, 2010, 5(6), 180-181.

34. Dhandhukia, S. N. and Patel, P. K., Selection of nesting sites and nesting material in common myna (Acridotheres tristis) in an urban area. Int. J. Pharm. Life Sci., 2012, 3(8), 1897-1904.

35. Gupta, N., Gore, T. and Srivastava, A., Foraging tolerance of the Indian myna towards the house sparrow: an observation. Int. J. Innov. Sci., Eng. Technol., 2014, 1(5), 162-165.

ACKNOWLEDGEMENTS. I would like to thank my family for providing funds to carry out this research as part of my Ph D. We thank Dr Upamanyu Hore and Dr C. Murli Krishna (Amity Institute of Forestry and Wildlife, Amity University, Noida) for help with data analysis and for valuable suggestions, and Dr Anindita Sarkar Chaudhuri (Department of Geography, Indraprastha College of Women, Delhi University, Delhi) for making the map of the study area.

Received 7 March 2019; revised accepted 27 December 2019

doi: $10.18520 / \mathrm{cs} / \mathrm{v} 118 / \mathrm{i} 8 / 1304-1309$ 